\title{
Three-day clotrimazole treatment in candidal vulvovaginitis
}

\author{
G. MASTERTON, ISABELLA R. NAPIER, JEAN N. HENDERSON, AND \\ JANE E. ROBERTS
}

From Glasgow

SUMMARY The accepted modern practice is to treat each sexually transmitted disease with the shortest possible course of treatment consistent with success. In candidal vulvovaginitis, six days is the minimum period that has so far been found to be successful, but we report here a further reduction to three days. Patients were given two clotrimazole pessaries nightly for three consecutive nights; the overall success rate was $89.4 \%$ one month after treatment. This compares favourably with the $93 \%$ cure rate reported with the six-day course of clotrimazole. With both the long and short courses, patients having their first attack of genital candidosis responded better than those with a history of previous infection. Short courses of clotrimazole treatment are particularly valuable in dealing with uncooperative women who stop treatment at the earliest possible moment. Clinical and laboratory diagnostic pitfalls and their possible influence upon the therapeutic outcome are also discussed.

\section{Introduction}

Nearly half of the patients suffering from sexually transmitted disease seem temperamentally incapable of taking any prolonged course of treatment (Masterton et al., 1976). In some infections, single session treatment has resolved this problem but so far six days is the shortest reported period for treating candidal vulvovaginitis (Weuta, 1972 ; Tamura et al., 1973 ; Couchman, 1974 ; Higton, 1974 ; Kobayashi and Amenomori, 1974 ; Oates and Davidson, 1974 ; Tan et al., 1974). In Glasgow in a single blind trial using nystatin pessaries for the control group a six-day clotrimazole pessary regimen gave a cure rate of $93 \%$ when assessed one month after starting treatment (Masterton et al., 1975). However during and after this trial some women failed to complete the six-day course so we tried the effect of reducing the duration of treatment to three days.

\section{Method}

Women satisfying the following criteria were admitted to the drug trial:

Address for reprints: Dr G. Masterton, Department of Sexually Transmitted Diseases, 67 Black Street, Glasgow G4 OEF

Received for publication 20 September 1976
1. Those with signs and symptoms suggesting candidal vulvovaginitis.

2. Those with pseudohyphae (not just spores seen on microscopical examination).

3. Those with Candida albicans identified on culture (to eliminate observer bias this was done at an independent mycological department).

Such patients were instructed to insert two clotrimazole $100 \mathrm{mg}$ pessaries high into the vagina for three consecutive nights. They were re-examined one and four weeks later. Subjective and objective findings were recorded at each visit on a four-point scale and Gram-stained smears were examined immediately for pseudohyphae. High vaginal swabs were sent to the laboratory for cultural confirmation. No other anti-fungal treatment was used during the trial and the data were subsequently analysed by an independent statistician.

\section{Results}

Because 57 women defaulted only 103 of those originally treated could be assessed.

Most improvements in the signs and symptoms took place within the first week. Statistically there did not appear to be any relationship between the improvement and age, parity, or duration of 
infection. When the subjective and objective impressions of the amount of residual vaginal discharge were compared, the clinician appeared to grade the degree of discharge more severely than did the patient, Table 1 .

Table 1 Effect of treatment on signs and symptoms

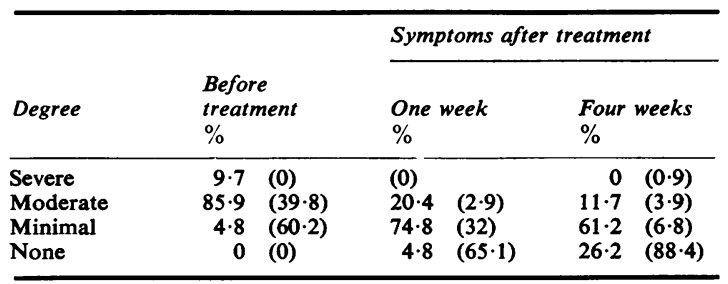

Symptoms shown in parentheses

On less controversial grounds, judging by negative cultural results at one week the overall 'cure' rate was $99.1 \%$. By the end of the fourth week, 10 $(9.7 \%)$ more patients had relapsed making the overall 'cure' rate $89.4 \%$. However if the patients were divided into those with a previous history of genital candidosis and those having their primary candidal infection, the rates were $75.7 \%$ and $95.7 \%$ respectively. In the long-term 66 of those originally treated were followed-up for a minimum period of six months. During this time another nine-that is, $13.6 \%$ of the original group-developed further genital candidosis, and once again those having their primary infection were least affected with an $88.3 \%$ 'cure' rate compared to $53 \cdot 5 \%$.

\section{Discussion}

One-third of the patients originally treated failed to follow instructions and could not be assessed. Many women regard some vaginal discharge as being normal; this is an attitude which may partly explain why they discontinued treatment as soon as the compelling symptoms of itching and burning had disappeared, generally about the third or fourth day after treatment had started. Thus uncooperative attitudes are not solely confined to the feckless patients; some apparently dependable women behave in the same manner. Hence the most successful treatment is likely to be the one which is effective in the shortest period of time.

Because of these differences between the objective and subjective impressions we based our judgement upon the cultural findings. We noted a disagreement between the microscopical and cultural findings at the first examination after treatment. In one-third of the patients scanty fungal elements were visible on microscopical examination but these could not be cultured and clinically the patients continued to improve. It may be that those fungi which took up the Gram stain had been severely damaged but had not then completely disintegrated. Whatever the true explanation cultural examination appears essential.

For practical reasons anti-fungal treatment sometimes anticipated the cultural confirmation. Thus some women who were believed on clinical or microscopical grounds to be suffering from genital candidosis were treated with clotrimazole. When this opinion was not confirmed by culture the women were not included in the trial but it was noted that only $109(70.3 \%)$ of the 155 patients so diagnosed had benefited from three-day clotrimazole treatment at the first examination. Obviously culturally-proved cases only should be included in trials of anti-fungal preparations otherwise inaccurate conclusions are probable.

We did not exclude from the trial patients with a previous history of genital candidosis but we assessed their results separately. At four weeks the failure rate was $24.3 \%$ in patients with a previous history of genital candidosis, but it was much less $(4.3 \%)$ in those women having their primary infection. Thus the overall results of any clinical trial are likely to be influenced by the proportional representation of these two types of patients in the group under treatment. For example, three years ago (Masterton et al., 1975) we carried out a single blind trial of six-day clotrimazole pessary treatment using identical trial parameters. One-fifth of these patients had a previous history of genital candidosis and the overall failure rate was $7 \%$. In the current three-day trial one-third of the women had had genital candidosis previously and this time our overall failure rate was $10 \cdot 6 \%$ (Table 2 ).

Table 2 Comparison of two clotrimazole regimens in the treatment of confirmed genital candidosis

\begin{tabular}{lllll}
\hline & & \multicolumn{2}{l}{ Patients assessed at four weeks } \\
\cline { 3 - 5 } $\begin{array}{l}\text { Length of } \\
\text { course } \\
\text { (days) }\end{array}$ & $\begin{array}{l}\text { Previous } \\
\text { candidosis }\end{array}$ & No. & $\begin{array}{l}\text { Culture } \\
\text { positive } \%\end{array}$ & $\begin{array}{l}\text { Overall } \\
\text { culture } \\
\text { positive } \%\end{array}$ \\
\hline 3 & No & 70 & $3(4 \cdot 3)$ & 10.6 \\
& Yes & 33 & $8(24 \cdot 3)$ & \\
6 & No & 45 & $12 \cdot 2)$ & $7 \cdot 0$ \\
& Yes & 12 & $3(25)$ & \\
\hline
\end{tabular}

These results are satisfactory but only in the short term. In some of the patients who were followed-up for a minimum period of six months genital candidosis reappeared. Although we have no idea of the precise aetiology of these recurrences, relapses, or reinfections the result was that the 'cure' rate in those having their primary infection decreased to 
$88.3 \%$ and in those women who had had previous candidosis the 'cure' rate was $53 \cdot 5 \%$. Obviously more attention must be given to the local, systemic, and personal factors which may affect the continuation of candidal infection.

We concluded that the three- and the six-day clotrimazole pessary regimens gave satisfactory results and can be recommended for uncooperative patients who readily reject the discipline of regular medication. Such short-term treatment is particularly effective if the patient is suffering from genital candidosis for the first time, but abbreviated regimens are not recommended for patients who have a history of candidosis. Such patients should receive a longer course of treatment, for instance 12 days of clotrimazole, and a thorough search should be made for probable precipitating factors.

We thank our nursing and medical colleagues for their co-operation and Dr T. F. Elias-Jones, Director City Laboratory, for the laboratory investigations. Above all we thank Dr C. S. Good, Senior Medical Advisor, Bayer Ltd for his valuable assistance in preparing this paper.
References

Couchman, J. M. (1974). A preliminary report on a trial of clotrimazole against vaginal candidiasis in venereology. Postgraduate Medical Journal, 50, Supplement 1, 93-94.

Higton, B. K. (1974). A trial of clotrimazole and nystatin in vaginal candidiasis. Postgraduate Medical Journal, 50, Supplement 1, 95-97.

Kobayashi, T., and Amenomori, Y. (1974). Results of a clinical investigation of clotrimazole (Canesten), a new antimycotic substance, in the therapy of vaginal fungal infections. Journal of International Medical Research, 2, 366-369.

Masterton, G., Henderson, J., Napier, I. R., and Moffett, M. (1975). Six day clotrimazole therapy in vaginal candidiasis. Current Medical Research and Opinion, 3, 83-88.

Masterton, G., Moffett, M., Henderson, J., and Napier, I. R. (1976). Six day clotrimazole (Canesten) therapy in vaginal candidiasis. Münchener medizinische Wochenschrift, 118, Supplement 1, 56-59.

Oates, J. K., and Davidson, F. (1974). Treatment of vaginal candidiasis with clotrimazole. Postgraduate Medical Journal, 50, Supplement 1, 99-102.

Tamura, S., Kuramoto, H., Yamada, T., Majima, H., and Miyamoto, H. (1973). The therapy of candida vaginitis and candida vulvovaginitis with a new antimycotic substance, clotrimazole. Current Medical Research and Opinion, 1, 540-546.

Tan, C. G., Milne, L. J. R., Good, C. S., and Loudon, J. D. O. (1974). A comparative trial of six day therapy with clotrimazole and nystatin in pregnant patients with vaginal candidiasis. Postgraduate Medical Journal, 50, Supplement 1, 102-105.

Weuta, H. (1972). Clotrimazole vaginal tablets, cream and solutionclinical investigation in an open study. Drugs made in Germany, 15, 121-132. 